\title{
APPROXIMATE SOLUTIONS FOR THE INTERRUPTION OF CREEP AND GLIDE BY AVALANCHE DEFENSES
}

\author{
By R. J. Evans and J. A. Langdon \\ (Department of Civil Engineering, University of Washington, Seattle, Washington 98195, \\ U.S.A.)
}

\begin{abstract}
This paper presents a numerical calculation procedure for the stress and deformation analysis of a snow mass which is creeping and gliding on an inclined surface and which may, in addition, be restrained by rigid obstacles. The analysis is based on the assumption that the velocity profile at any position in the snow-pack is linear, that is, that sections initially plane remain plane during deformation. Such motion has been observed to occur in the neutral zone and is certainly true at a rigid barrier; accordingly, it appears to be reasonable to restrict the velocity field to be plane everywhere. A constitutive law for steady creep is used which is consistent with the observed neutral zone motion. The solution procedure is illustrated by its application to some problems of avalanche defense barriers. The cases investigated include: continuous barriers, cylindrical barriers, and barriers of finite width. Barrier forces and the extent of back-pressure zones are given.

RÉsumé. Solutions approximatives pour le problème de l'interruption du fluage et du glissement par les ouvrages de défense contre l'avalanche. Cet article présente un programme de calcul numérique pour l'analyse des efforts et des déformations d'une masse de neige en train de fluer et de glisser sur une surface inclinée et qui peut, de surcroît, être freinée par des obstacles fixes. L'analyse est basée sur l'hypothèse que le profil des vitesses à quelque point que ce soit dans le manteau neigeux est linéaire, c'est-à-dire que les sections initialement planes restent planes durant la déformation. On a observé des mouvements de ce type dans les zones neutres et c'est certainement vrai contre un obstacle rigide; c'est pourquoi, il semble raisonnable de supposer que le champ des vitesses est plan partout. Une loi pour le fluage constant est utilisée qui est cohérente avec le mouvement observé dans la zone neutre. Le programme solution est illustré par son application à quelques problèmes d'ouvrages pare-avalanches; les cas traités comprennent: des ouvrages continus, des obstacles cylindriques, et des ouvrages de largeur finie. Les valeurs des contraintes sur les ouvrages et l'étendue de la zone de compression en amont sont données.
\end{abstract}

Zusammenfassung. Näherungslösungen für die Hemmung von Kriechen und Gleiten durch Lawinenverbauungen. Diese Arbeit enthält ein Verfahren zur rechnerischen Analyse der Spannung und Verformung von Schneemassen, die auf einem geneigten Hang kriechen und gleiten und ausserdem durch ein starres Hindernis gehemmt werden mögen. Die Analyse beruht auf der Annahme, dass das Geschwindigkeitsprofil an jeder Stelle des Schneepackens linear ist, d.h. dass urspünglich ebene Querschnitte während der Deformation eben bleiben. Das Auftreten einer derartigen Bewegung wurde in der neutralen Zone beobachtet; sie herrscht sicherlich vor einem starren Hindernis. Dementsprechend erscheint es angebracht, das Geschwindigkeitsfeld überall als eben anzunehmen. Grundlegend wird ein Gesetz für stetiges Kriechen benutzt, das mit der beobachteten Bewegung in der neutralen Zone konsistent ist. Das Lösungsverfahren wird in seiner Anwendung auf einige Probleme der Lawinenverbauung erläutert; die Untersuchung erstreckt sich den Fall langgestreckter und zylindrischer Hindernisse sowie von Hindernissen mit bregrenzter Ausdehnung. Die Hemmkräfte und das Ausmass der Rückstauzonen werden angegeben.

\section{INTRODUCTION}

This paper presents the development and application of a solution procedure designed to describe the deformation of snow-packs due to creep and glide. An element for such a solution was first developed by Brown and Evans (1975), but this element was restricted to the case where deformation was plane, that is, for motion down a wide slope of constant gradient. The element described here conforms to the same neutral zone kinematics as did the BrownEvans model but permits the general motion to vary both down and across the slope. This allows a more general type of problem to be solved, for example, that of the creep and glide of snow on slopes with arbitrary arrangements of static defense structures. The main advantage of such a procedure is that it will permit an approximate theoretical investigation of the various static avalanche defense arrangements.

In the first part of this paper the element is developed. It is then used to investigate further the continuous barrier problem and to examine briefly some other barrier arrangements. The paper concludes with some discussion into applications of the work. 
The element

Observations into the creep and glide of snow in the Cascade Mountains of the United States of America (Brown and others, 1972; McClung, unpublished) show that the creep profile throughout the thickness of the snow is approximately linear. Such motion has also been observed in the Swiss Alps (Haefeli in Bader and others, 1939, p. 143).

A calculation of forces on rigid obstacles in the glide path requires, in general, some approximate numerical procedure, so it appears reasonable to make use of a method which restricts motion everywhere to conform to that observed in the neutral zone.

The snow is assumed to be linearly viscous under conditions of steady creep and to be isotropic but non-homogeneous. The creep modulus varies linearly with depth and is zero at the upper surface. The inhomogeneity may either be a material property resulting from some deposition process, or may be stress induced, that is, for an isotropic material the creep modulus may depend linearly on hydrostatic stress. No field evidence is available to favour either law; both are considered here but the former is mainly used.

The element is a triangular prism extending the depth of the snow-pack. Sections which are initially plane remain plane during deformation, and the motion thus conforms to the observed kinematics in the neutral zone and at rigid barriers.

For all subsequent calculations the snow thickness and density are taken to be constant, the glide law is taken to be linear, in other words, the restraining tangential traction is proportional to the glide velocity and the glide modulus $\beta$ is taken to be constant. The steady creep behavior is characterized by the viscous analogs of Young's modulus (the creep modulus $E$ ) and Poisson's ratio $\nu$. The behavior of $E$ was described above, $\nu$ is taken to be constant. The time during which the motion is studied is taken to be short enough so that geometry changes may be ignored.

Boundary conditions prescribe either zero velocity, zero traction, or velocities which are proportional to traction, so the problem is equivalent to one of linear elasticity and elementary finite-element procedures are applicable. The pentahedral element used is shown in Figure $\mathrm{I}$. The $z$ coordinate is normal to the slope and the depth of the pack is $h$. The displacement is such that the strain in any section perpendicular to the $z$-axis is constant and strains vary linearly in the $z$-direction. Only motion in the $z$-plane is considered; any settlement and resulting tangential force or obstacles may be considered separately. The $12 \times 12$ element

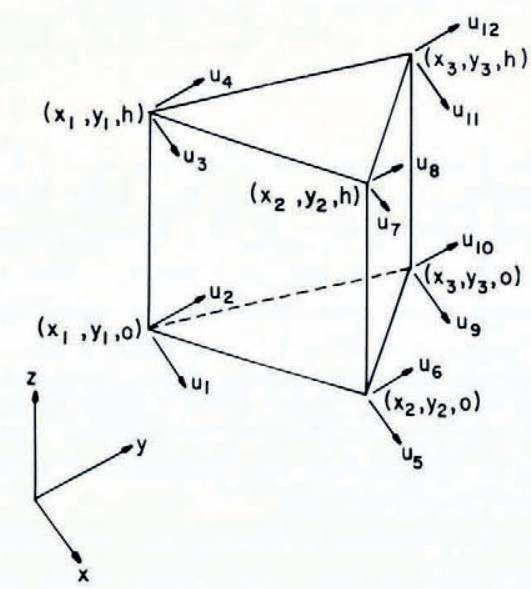

Fig. I. The element used in the general solution. 
stiffness-rate and glide-stiffness-rate matrices are given in the Appendix. Their calculation is lengthy but straightforward (Langdon, unpublished) and details are not shown here. Specific examples are now given; they all involve uniform slopes.

\section{Continuous barrier Problems}

If the $x$-axis is up the slope, referred to in Figure $\mathrm{I}$, the element is characterized by

while the motion requires that

$$
x_{2}=x_{3} \text {, }
$$

$$
\begin{gathered}
u_{5}=u_{9}, \\
u_{7}=u_{\mathrm{II}}, \\
u_{2}=u_{4}=u_{6}=u_{8}=u_{\mathrm{Io}}=u_{\mathrm{I} 2}=0,
\end{gathered}
$$

and the 4 degrees-of-freedom element is essentially equivalent to that of Brown and Evans (1975). This arrangement permits the effect of the kinematic restriction to be investigated by comparison with a finite-element, plane-strain formulation (McClung, unpublished). The elements used are shown in Figure 2 and the resultant barrier force is used as a basis of comparison (there is also, in general, a resultant barrier moment which is not discussed here).

The barrier force $F$ may be expressed as

$$
F=\rho g h^{2} c,
$$

where $\rho g$ is the snow density and

$$
c=\frac{\mathrm{I}}{2} \frac{\tilde{\nu}}{\mathrm{I}-\tilde{\nu}} \cos \alpha+c_{\mathrm{I}} \sin \alpha .
$$

In Equation (2) $\tilde{\nu}$ is the effective Poisson's ratio, $\alpha$ is the slope angle and $c_{1}$ is a measure of the force due to creep and glide. The first term on the right-hand side of Equation (2) is due to static pressure (Brown and others, 1972) and $c_{1}$ is most conveniently represented in terms of $\nu$ and $A$, the relative neutral-zone stagnation depth. $A$, in turn, may be shown to be given by the relation

$$
A=\frac{E_{0} h}{2 \beta(\mathrm{I}+\tilde{\nu})},
$$

where

$$
E=E_{0} \frac{h-z}{h},
$$

is the glide modulus at depth $z$ (Langdon, unpublished).

An extensive parameter study by Langdon (unpublished) for the full-depth element has found $c_{\mathrm{I}}$ to be given accurately by the empirical relation

$$
c_{\mathrm{I}}=0.592+0.4 \tilde{\nu}+A+0.4 A^{2}+0.07 \tilde{v} A,
$$

in the ranges

$$
0 \leqslant A \leqslant 0.8 \quad \text { and } \quad 0 \leqslant \tilde{\nu} \leqslant 0.5
$$

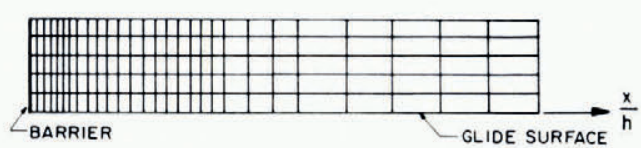

(a)

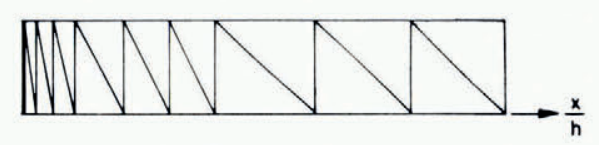

(b)

Fig. 2. Element arrangements for continuous barriers. (a) Elevation of the two-dimensional arrangement. (b) Plan of twodimensional full-depth arrangement (both diagrams are drawn to the same scale). 
The values found for $c_{1}$ are slightly higher than those from the finite-element, plane-strain program, the greatest difference in $c_{\mathrm{I}}$ being $8 \%$. Comparison with the finite-element planestrain solution also shows that although some deviation from the linear creep profile occurs in the back-pressure zone, this deviation is relatively small (not exceeding $10 \%$ ) and is insignificant except near the barrier. The full-depth element also gives back-pressure zones and glide profiles which are nearly identical to the plane-strain procedure.

The agreement between solutions is not quite so close for the stress-induced inhomogeneous constitutive law (Langdon, unpublished). This is because, for the plane-strain solution, the variation in modulus can be more closely approximated than for the solutions of the full-depth element for which the modulus can only be made dependent on the average hydrostatic stress over the entire depth of the snow. Because the $z$-direction stress $\sigma_{z}$ is not determined in this solution, the hydrostatic stress, in turn, cannot be accurately determined.

\section{Pole BARriers}

These are idealized as a line barrier normal to the slope. Figure 3 shows a r 20-element arrangement which was used for these problems. In order to obtain good approximations for forces and velocities it was necessary to have small elements near the pole.

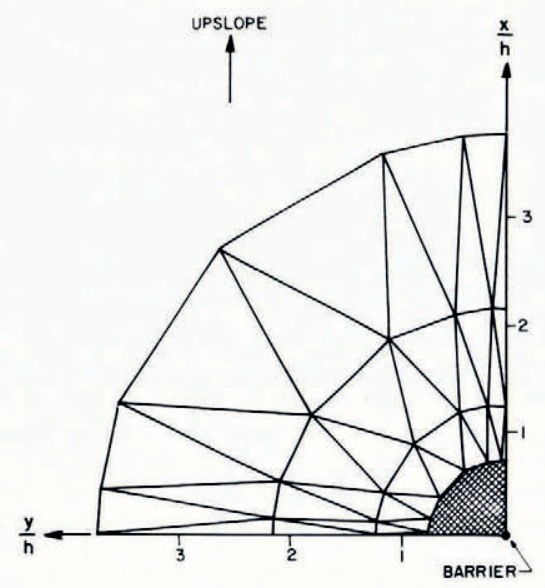

Fig. 3. Element arrangement for pole barriers (shaded area contains 81 similar elements diminishing in size).

The element arrangement takes advantage of symmetry and antisymmetry. The boundary condition at the pole is zero velocity in both directions. The boundary conditions along both axes are zero $y$ velocity and zero $x$ traction. This boundary condition on the $y$-axis arises as follows: Although the entire problem is not antisymmetric, it may be thought of as the sum of two cases, (I) the uniform creep and glide, and (2) the superimposed line force at the pole to make the total velocity there zero. The $x$ traction and $y$ velocity for case (I) are zero everywhere, whereas case (2) is antisymmetric about the $y$ axis and hence the $x$ traction and $y$ velocity are zero at the $y$-axis for this case. Thus the entire problem may be solved by considering the quarterspace and by using boundary conditions of symmetry about the $x$-axis and antisymmetry about the $y$-axis. The other boundary corresponding to the neutral zone has zero $x$-direction traction and zero $y$-direction velocity.

A parameter study varying $A$ and $v$ for the materially inhomogeneous constitutive law results in the following empirical equation for barrier force (excluding static pressure)

$$
F=\rho g h^{3} c_{3} \sin \alpha,
$$


where

$$
c_{3}=0.25^{2}+0.107 \nu+0.692 A-0.040 A^{2}+0.267 \nu A .
$$

This barrier force is approximately equal to the force acting on a continuous barrier over a length of one-half the snow depth. Equation (7) is within I \% of the results for all cases studied in the range between $0 \leqslant A \leqslant 0.8$ and $0 \leqslant \nu \leqslant 0.375$.

The glide and surface velocity contours in the $x$-direction as well as the shear stress $\tau_{x z}$ can be closely approximated by ellipses as shown in Figure 4. As would be expected, the extent of the back-pressure zone in the $x$-direction is considerably less than it is for a continuous barrier. The $90 \%$ contour for $A=0.2$ and $\nu=0.2$ for the pole barrier is at $x=0.5 \mathrm{I} h$ whereas for the continuous barrier it is at $x=\mathrm{I} .8 \mathrm{o} h$. Velocity components in the $y$-direction as well as $\tau_{y x}$ are small.

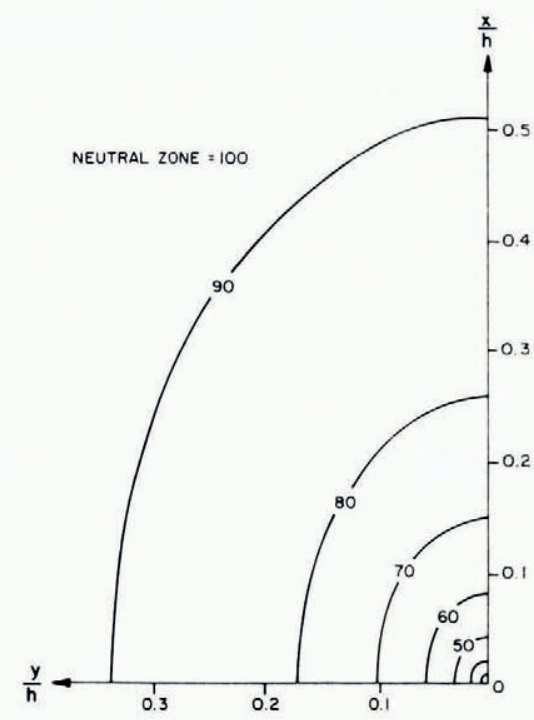

Fig. 4. Approximate contours of $x$-velocities and $\tau_{x z}$ for pole barrier where $A=\nu=0.2$.

\section{Pole barrier Restrained AT THE GRound only}

This problem, which can be considered an approximation to a very short obstacle interrupting glide, was studied for the specific conditions $A=\nu=0.2$. The value of $c_{3}$ for this case was $15 \%$ of that for a rigid pole barrier. The $x z$ shear stress at the barrier is actually increased by some $30 \%$, which implies that an isolated obstacle may increase the avalanche risk if, as must be expected, this stress influences avalanche formation.

\section{Cylindrical barriers}

Two cylindrical-barrier problems were solved using an element arrangement similar to that used for the pole-barrier problems. The snow was assumed to adhere to the barriers on all sides so that symmetry and antisymmetry boundary conditions could be used. Results were obtained for two cylinder diameters, $0.02 h$ and $0.06 h$. Such dimensions might correspond to trees; in snow $4 \mathrm{~m}$ deep the diameters corresponding to the above data are 80 and $240 \mathrm{~mm}$, respectively. The velocities and $\tau_{x z}$ can be approximated by ellipses as before. The eccentricity is no longer constant near the barrier, and the back-pressure zone increases with increasing barrier size. For the case $A=0.2$ and $\nu=0.2$, values of $c_{3}$ in Equation (6) are 0.62 and 0.82 for diameters of $0.02 h$ and $0.06 h$, respectively. 


\section{Discontinuous BARRIERS}

An approximate solution for a semi-infinite barrier was obtained using the element arrangement shown in Figure 5; I8I elements are used here. Symmetry was not used because of velocity discontinuity conditions which were permitted across the barrier. In order to arrive at realistic boundary conditions, all surfaces were taken to be traction free except for the up-slope side of the barrier where the $y$-direction velocity was taken to be zero, and at the outer boundary at $y=2 h$ where the $x$-direction velocity was set equal to zero. These boundary conditions permit a separation between the snow and the barrier on the down-slope side of the barrier.

In Figure 6, the barrier force is shown for the particular case $A=\nu=0.2$. The force intensity is large near the end of the barrier (theoretically there is a singularity here). The average force values are $30 Q$ for the first $0 . \mathrm{r} h$ along the barrier and r.6Q over the first $h$ of
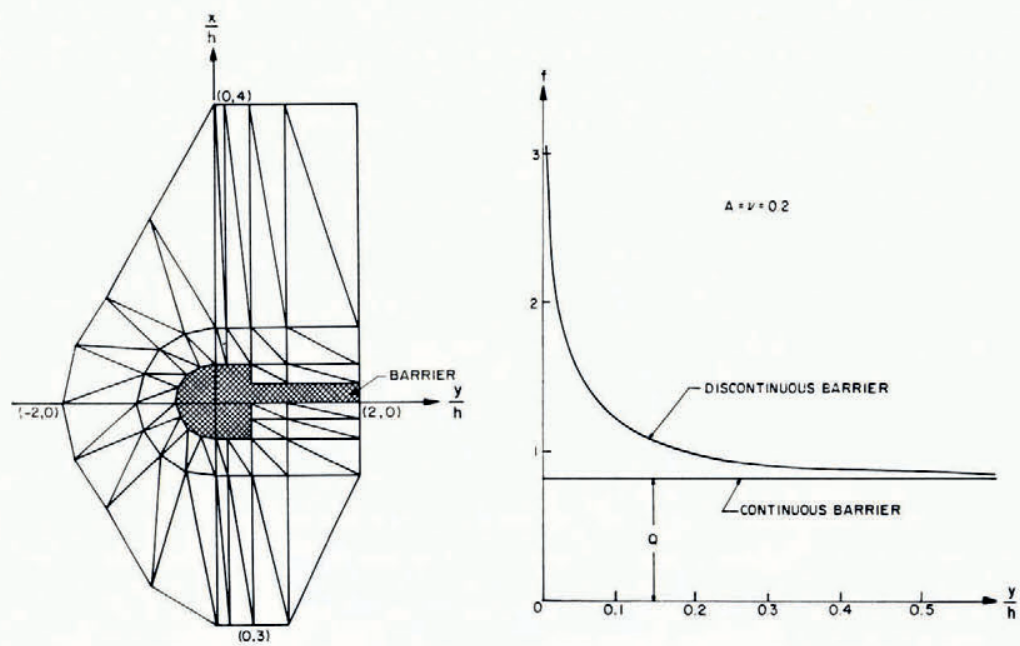

Fig. 5 (left). Element arrangement for discontinuous barrier (shaded area contains IO5 $_{5}$ similar elements diminishing in size) Fig. 6 (right). Force intensity near the end of a discontinuous barrier.

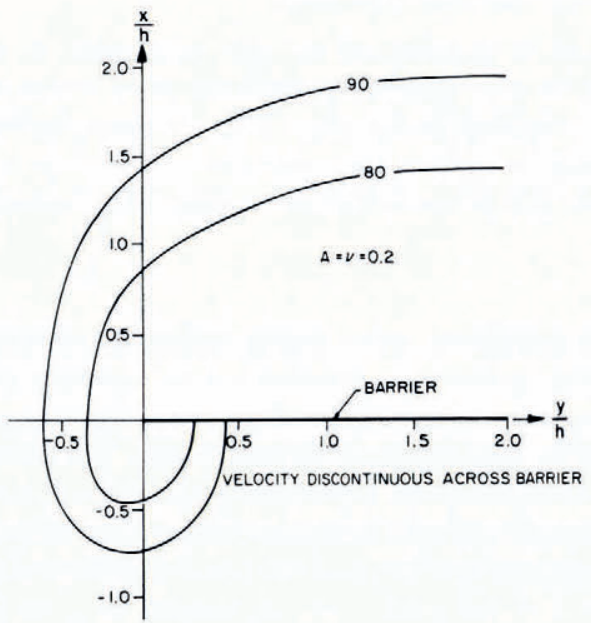

Fig. 7. Contours of $80 \%$ and $90 \%$ near the end of a discontinuous barrier. 
barrier length $(Q$ is the force intensity, neglecting static pressure, for the same creep and glide conditions on a continuous barrier). It may be seen, however, both from this Figure and from Figure 7, which shows the 80 and $90 \%$ value contours of the neutral zone, that the continuousbarrier solution describes the finite-barrier problem except in the immediate vicinity of the ends of the barrier.

\section{Congluding Remarks}

The procedure outlined in this paper provides an effective determination of the forces due to creep and glide on barriers which are perpendicular to the slope. The present method has led to a computationally efficient procedure in that relatively few degrees of freedom are required compared with conventional finite-element arrangements. The program has been written so that it is user oriented, and a FORTRAN listing is available from the authors. For continuous barriers, the forces are in reasonable agreement with those of the Swiss guidelines. As shown by Brown and Evans (1975), however, the forces in the present analysis are not uniform with depth.

Experimental measurements are sparse. Those made at the Eidg. Institut für Schnee- und Lawinenforschung have been summarized by Salm (1977). The results are for very low glide and show considerable scatter. If $\nu$ is assumed to be 0.3 the values are rather lower than those predicted here by Equations (2) and (5).

Refinement of the element is possible; for instance, a variable-height element could be developed in a manner similar to that of Brown and Evans. The present model could also be used for arbitrary slopes by modifying element densities appropriately. This, however, would not take into account geometric incompatibilities at surfaces normal to the slope.

It does not seem appropriate to develop theoretical methods further until more experimental evidence is available on the material behavior of snow in creep and glide. Indeed, field measurements show wide variations in creep and glide, thus calculations such as those given here must be used with considerable caution. Certainly, mechanisms other than those considered here must be considered in connection with avalanche defense design. For instance, in the Cascade Mountains, slab avalanches often result from the formation of depth hoar at some intermediate snow depth. This procedure will, however, provide information for static avalanche control by the techniques of forestation or ground surface modification. It has been shown that the back-pressure zone for a pole barrier can be less than the snow depth. If it is assumed that the back-pressure zones of adjacent barriers must interact for effective avalanche control, then barrier spacing would have to be less than the snow depth.

\section{REFERENCES}

Bader, H., and others. 1939. Der Schnee und seine Metamorphose, von H. Bader, R. Haefeli, E. Bucher, J. Neher, O. Eckel, C. Thams, P. Niggli. Beiträge zur Geologie der Schweiz. Geotechnische Serie. Hydrologie, Lief. 3. [English translation: U.S. Snow, Ice and Permafrost Research Establishment. Translation 14, 1954.]

Brown, C. B., and Evans, R. J. [1975.] Effect of glide and creep on rigid obstacles. [Union Géodésique et Geophysique Internationale. Association Internationale des Sciences Hydrologiques. Commission des Neiges et Glaces.] Symposium. Mécanique de la neige. Actes du colloque de Grindelwald, avril 1974, p. 407-14. (IAHS-AISH Publication No. I 14. .)

Brown, C. B., and others. 1972. Slab avalanching and the state of stress in fallen snow, [by] C. B. Brown, R. J. Evans and E. R. LaChapelle. Journal of Geophysical Research, Vol. 77, No. 24, p. 4570-80.

Brown, C. B., and others. 1973. Incorporation of glide and creep measurements into snow slab mechanics, by C. B. Brown, R. J. Evans and D. McClung. U.S. Dept. of Agriculture. Forest Service. General Technical Report RM-3, p. 7-13.

Langdon, J. A. Unpublished. Interruption of the creep and glide of snow by avalanche defenses. [M.S. thesis, University of Washington, 1975.]

McClung, D. M. Unpublished. Avalanche defense mechanics. [Ph.D. thesis, University of Washington, 1973.]

Salm, B. 1977. Snow forces. Journal of Glaciology, Vol. 19, No. 81, p. 67-100. 
where

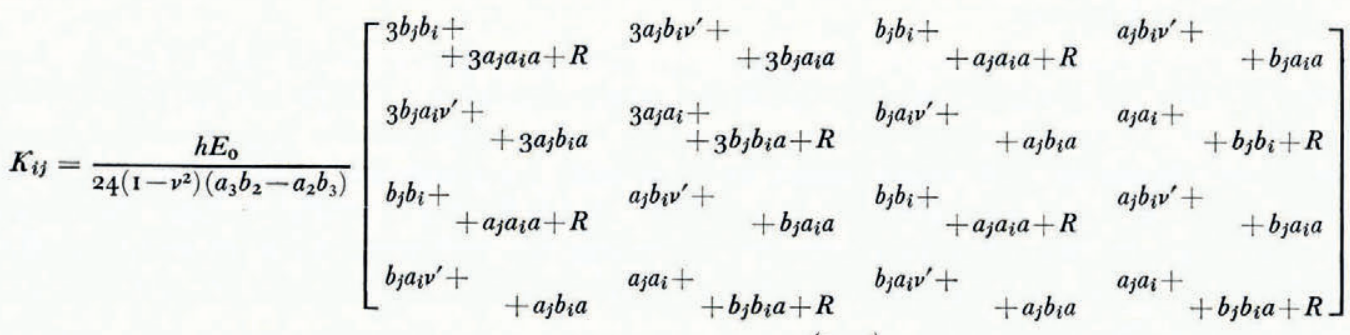

$$
\begin{aligned}
& R=2 c \text { if } i \neq j \quad a=\frac{(\mathrm{I}-\nu)}{2} \\
& R=4^{c} \quad \text { if } \quad i=j \quad \nu^{\prime}=\frac{\nu}{\mathrm{I}-v^{2}} \\
& a_{\mathrm{I}}=x_{3}-x_{2} \quad b_{\mathrm{I}}=y_{2}-y_{3} \\
& a_{2}=x_{1}-x_{3} \quad b_{2}=y_{3}-y_{1} \quad c=\frac{\left(a_{3} b_{2}-a_{2} b_{3}\right)^{2} a}{h^{2}} \\
& a_{3}=x_{2}-x_{1} \quad b_{3}=y_{1}-y_{2} \\
& \text { Element stiffness matrix (see Fig. I) } \\
& \mathbf{G}=\left[\begin{array}{lll}
G_{11} & G_{12} & G_{13} \\
G_{21} & G_{22} & G_{23} \\
G_{31} & G_{32} & G_{33}
\end{array}\right]
\end{aligned}
$$

where

$$
G_{i j}=\frac{\beta\left(a_{3} b_{2}-a_{2} b_{3}\right)}{24}\left[\begin{array}{cccc}
d & 0 & 0 & 0 \\
0 & d & 0 & 0 \\
0 & 0 & 0 & 0 \\
0 & 0 & 0 & 0
\end{array}\right]
$$

and

$$
\begin{aligned}
& d=2 \text { if } i=j \\
& d=\mathrm{I} \text { if } i \neq j
\end{aligned}
$$

Glide stiffness matrix

\section{DISGUSSION}

B. SAlm: According to Swiss experience and theoretical considerations, the force on a confined structure depends to a much higher degree on the glide factor (or stagnation depth) than the force on an unconfined structure. How do your investigations show this relationship?

R. J. Evans: As Equation (3) shows, the force is unchanged as long as $E_{0} / \beta$ remains constant. For $E_{0}$ constant, $\beta$ varying, the dependence on $\beta$ may be deduced from the same equation. 
T. LANG: Is the ratio of surface dimension to the depth dimension of your reported element a sensitive parameter for numerical stability when the ratio is small compared to unity?

Evans: We found no sensitivity even for values of $h$ lower than shown here. 